\title{
Artículo científico
}

\section{Rhodnius pallescens microsatellite markers for population genetic analysis in Rhodnius ecuadoriensis: preliminary assessment}

\section{Marcadores de microsatélite de Rhodnius pallescens para análisis genéticos poblacionales en Rhodnius ecuadoriensis: Evaluación preliminar}

\author{
Sofia I. Muñoz-Tobar¹, Fernando Abad-Franch² and Mario J. Grijalva1,3* \\ ${ }^{1}$ Centro de Investigación para la Salud en América Latina, Pontificia Universidad Católica del Ecuador, Quito, \\ Ecuador \\ ${ }^{2}$ Centro de Pesquisa René Rachou - Fiocruz Minas Gerais, Belo Horizonte, Brazil \\ ${ }^{3}$ Infectious and Tropical Disease Institute, Biomedical Sciences Department, Ohio University Heritage College of \\ Osteopathic Medicine, Irvine Hall, Athens, Ohio 45701, USA \\ *grijalva@ohio.edu \\ https://doi.org/10.26807/remcb.v40i2.763
}

Recibido 05-07-2019 ; Aceptado 25-09-2019

\begin{abstract}
RESUMEN.- Rhodnius ecuadoriensis Lent \& León (Hemiptera: Reduviidae) es el prinicipal vector de la enfermedad de Chagas en Ecuador, donde la estructura genética de sus poblaciones es poco conocida. Nosotros probamos seis Repeticiones Cortas en Tamdem (RCT) de $R$. pallescens Barber en poblaciones selváticas y domésticas de R. ecuadoriensis. Dos microsatelites fueron monomórficos, dos dieron resultados ambiguos y dos fueron polimórficos (16 y 19 alelos) y fueron utilizados para análisis. Los resultados de las frecuencias alélicas, AMOVA y los pruebas Bayesianas para genética favorecen la teoría de la existencia de una sola población. Estos resultados preliminares sugieren que las poblaciones selváticas y domésticas de R. ecuadoriensis intercambian frecuentemente migrantes. Por consiguiente el control de la Enfermedad de Chagas requiere vigilancia entomológica continua en la costa del Ecuador.
\end{abstract}

PALABRAS CLAVES: Enfermedad de Chagas, Ecuador, microsatelites, Rhodnius

ABSTRACT.- Rhodnius ecuadoriensis Lent \& León (Hemiptera: Reduviidae) is a major Chagas disease (CD) vector in Ecuador, but little is known about its population genetic structure. We tested six Short Tandem Repeats (STRs) from $R$. pallescens Barber in wild and synanthropic R. ecuadoriensis populations. Two STRs were monomorphic, two yielded ambiguous alleles, and two were polymorphic (16 and 9 alleles) and used for analysis. Allele frequencies, AMOVA, and a Bayesian population structure test all favored a single-population hypothesis. These preliminary results suggest that local wild andsynanthropic R. ecuadoriensis populations frequently exchange migrants; long-term CD control will therefore require continuous entomological surveillance in coastal Ecuador.

KEY WORDS: Rhodnius, Chagas disease, Ecuador, STRs. 


\section{INTRODUCTION}

Chagas Disease (CD), caused by Trypanosoma cruzi and transmitted via the feces of infected triatomine bugs, is endemic in western Ecuador Rhodnius ecuadoriensis is the main vector in the coastal region (Grijalva et al., 2010, 2012, 2014), where it occupies both artificial and sylvatic ecotopes - mainly Phytelephas aequatorialis palm trees and squirrel nests (Abad-Franch et al. 2001, 2005; Grijalva et al. 2012, 2014; Suárez-Dávalos et al. 2010). Quantitative phenotypic analyses suggest that wild populations are involved in the re-infestation of insecticide-treated households (Villacís et al. 2010, Grijalva et al. 2014), which is common in central coastal Ecuador (Grijalva et al. 2011; 2014). Yet, the population dynamics of this vector species remain largely unknown; in particular, powerful molecular genetics tools have never been used for the study of inter-population relationships in $R$. ecuadoriensis as they have in other important $\mathrm{CD}$ vectors (e.g., Fitzpatrick et al. 2008). Here we address $R$. ecuadoriensis population connectivity in central coastal Ecuador by testing the utility of Short Tandem Repeat (STR) markers developed for the closely-related species, R. pallescens (Harry et al. 1998, Abad-Franch et al. 2009).

\section{MATERIAL AND METHODS}

Fieldwork was conducted in 2009-2010 in the province of Manabí, where CD is endemic and insecticide-based vector control strategies perform poorly (Grijalva et al. 2011). Triatomines were manually collected in domestic-peridomestic structures and nearby sylvatic habitats in eight localities (Fig. 1).

All collections were conducted following protocols approved by the Institutional Review Boards of Catholic University of Ecuador and Ohio University. Overall, 270 specimens were studied, 150 collected in sylvatic habitats and 120 in artificial structures. Sampling included 100 individual ecotopes (1 to 16 bugs/ecotope, median $=2$, interquartile range 2 3 ), including squirrel nests (Sciurus stramineus), hen nests, houses, bird nests (Campylorrynchus fasciatus and one Synallaxis sp.), mouse and rat nests, guinea pig enclosures, and timber piles. Specimens included all stages except first-instar nymphs, with adults representing about $67 \%$ of the sample and evenly distributed in relation to sex. Hence, we are confident that our sample fairly represents local population diversity.

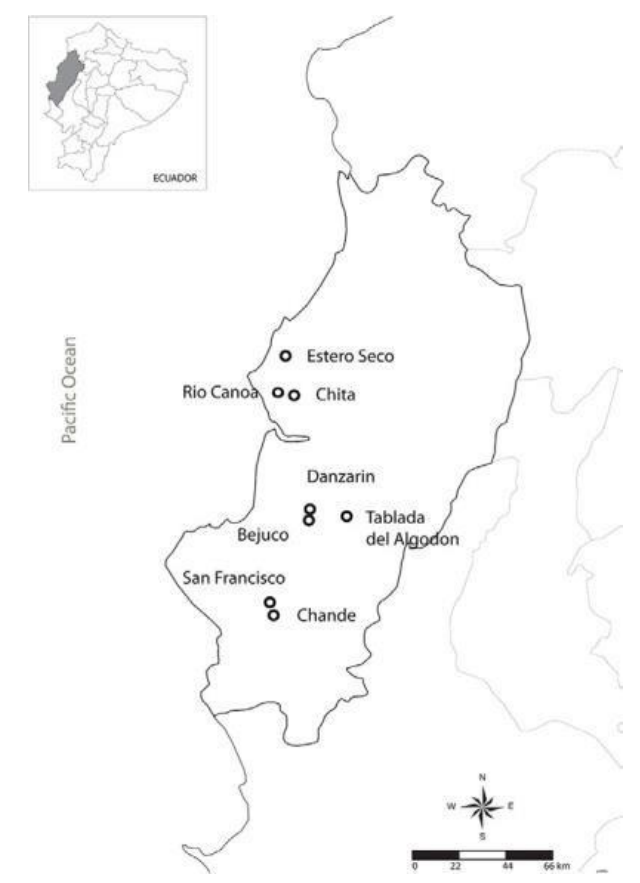

Figure 1. Map of Manabí province indicating the location of the sampled communities. Insert shows a map of Ecuador with the location of Manabí. 
DNA was isolated and purified using DNeasy ${ }^{\circledR}$ extraction kits (Qiagen) following the manufacturer's protocol for animal tissue. Microsatellite amplification followed a protocol modified from Harry et al. (1998), using primers designed for six loci (L3, L9, L13, L25, L43, L47) of $R$. pallescens, a species phylogenetically close to R. ecuadoriensis (Abad-Franch et al. 2009). For PCR, we used the GoTaq ${ }^{\circledR}$ Colorless Master Mix kit (Promega), adding $6.4 \mu \mathrm{l}$ of $\mathrm{MgCl}_{2} 25 \mathrm{mM}$, $0.4 \mathrm{pM}$ of each fluorochrome-labeled primer, and $10 \mathrm{ng} / \mu \mathrm{l}$ of DNA for a final reaction volume of $25 \mu \mathrm{l}$. PCR was carried out in a PTC-100® thermal cycler (MJ Research), with a denaturation step $\left(95^{\circ} \mathrm{C}\right.$ for $5 \mathrm{~min}$ ) followed by 40 cycles of denaturation (95 $\left.{ }^{\circ} \mathrm{C}, 30 \mathrm{sec}\right)$, annealing $\left(50^{\circ} \mathrm{C}, 30 \mathrm{sec}\right)$ and extension $\left(72{ }^{\circ} \mathrm{C}, 30 \mathrm{sec}\right)$, and a final extension step $\left(72^{\circ} \mathrm{C}\right.$, 5 min). For loci L13 and L43, a nested PCR was carried out using the product of the first PCR asthe template and the protocol above - except that no additional $\mathrm{MgCl}_{2}$ was used.

We first screened the full microsatellite panel with 30 randomly selected bug samples to check for polymorphism over all loci. This scan revealed that two loci were monomorphic (L9 and L25) and two
(L3 and L43) yielded ambiguous allele signatures that precluded confident scoring. These four loci were therefore disregarded in subsequent analyses, and only the two polymorphic markers yielding unambiguous alleles (L13 and L47) were used to analyze the full sample of triatomines. Genotyping was performed by capillary electrophoresis in an ABI 313xl with a standard G500 LIZ ladder (Applied Biosystems); fsa files from capillary runs were then analyzed with Peak Scanner ${ }^{\mathrm{TM}} 1.0$ for manual allele scoring. A total of 93 samples yielded no PCR product; results below are therefore based on 177 bugs, 82 from sylvatic and 95 from artificial ecotopes. Different analyses were conducted in Excel ${ }^{\circledR}$ spreadsheets, Arlequin 3.1 (Excoffier et al. 2005), and STRUCTURE 2.2 (Pritchard et al. 2000).

\section{RESULTS}

Overall, 16 alleles were identified for L13 and nine for L43; in both cases, allele frequencies were similar in wild and synanthropic populations, with only one L47 allele found at higher frequency among wild bugs (Fig. 2 and Table).

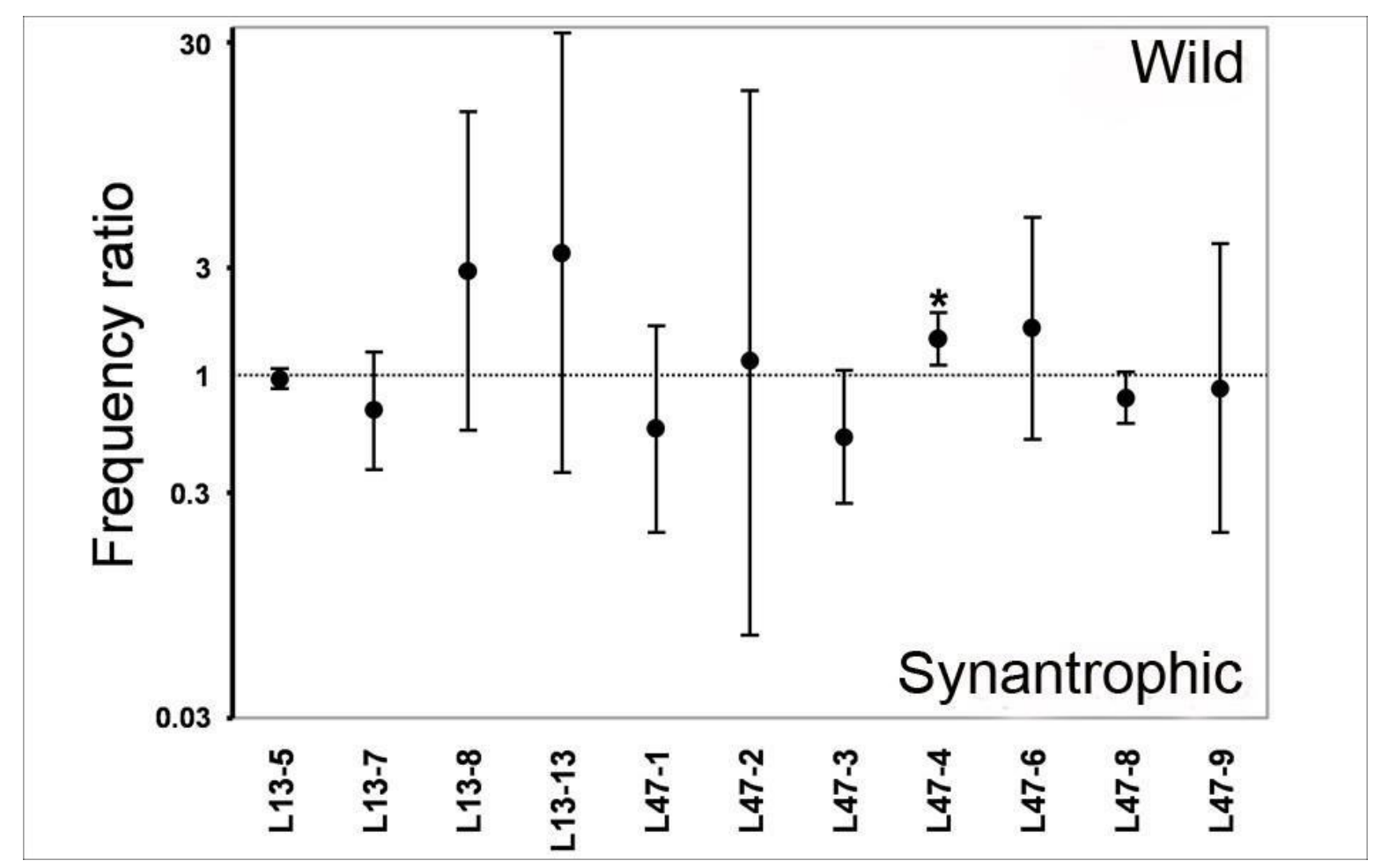

Figure 2. Allele frequency $(f)$ ratios, estimated as $f($ wild)/f(synanthropic), for 11 shared alleles on two microsatellite loci (L13 and L47) in Rhodnius ecuadoriensis populations. Point estimates (solid circles) and 95\% confidence intervals (CIs, between short horizontal lines) are shown, with allele codes given on the $\mathrm{x}$-axis. The asterisk indicates the only allele (L47-4) for which we found evidence of a higher frequency in one of the populations (wild); for the rest, the fact that CIs include 1 (horizontal dotted line) indicates that allele frequencies are not significantly different at the $5 \%$ level. 
Twelve rare L13 alleles, each with an overall frequency $<0.012$, were only found in either wild (six alleles) or synanthropic bugs (six alleles); this was the case for just two L47 alleles, found only in wild specimens (Table). A total number of 70 synanthropic $(73,68 \%)$ and 48 wild (58, $54 \%$ ) individuals were homozygotic for the L13 locus, with an overall observed heterozygosity $\mathrm{HO}=33,33 \%$. Homozygote figures for L47 were $71,58 \%(68 / 95)$ for synanthropic and 70,73\% (58/82) for wild populations; overall observed heterozygosity was therefore $\mathrm{HO}=28,81 \%$. L47 allele frequencies departed significantly from expectations under Hardy-Weinberg equilibrium among both synanthropic (expected heterozygosity $\mathrm{HE}=72,41 \%$, vs. $\mathrm{HO}=28,42 \%, \mathrm{p}<0,0001)$ and wild bugs ( $\mathrm{HE}=65,89 \%$, vs. $\mathrm{HO}=29,27 \%$, p < 0,0001 ), with exact p-values (Guo and Thompson
1992) estimated via a Markov chain of 100000 steps (1 000 discarded as burn-in) implemented in Arlequin 3.1. This heterozygote deficit is likely due to allelic dropout caused by poor primer specificity, although selection acting on genes located in the same chromosome region as L47 or random drift might also contribute to this finding; our preliminary dataset does not allow for a detailed appraisal of these alternatives.

Gene diversity was slightly higher in the wild $(0,799 \pm 0,023)$ than in the synanthropic population $(0,783 \pm 0,021)$. An analysis of molecular variance (AMOVA) suggested that an overwhelming proportion of genetic variation $(98,7 \%)$ lies among individuals within populations. Both AMOVA and an exact test of population differentiation suggest that allele frequencies in both populations are

Table 1. Allele frequencies of two microsatellite loci (L13 and L47) in wild and synanthropic populations of Rhodnius ecuadoriensis from coastal Ecuador

\begin{tabular}{|c|c|c|c|c|c|}
\hline \multirow[t]{2}{*}{ Locus-allele } & \multicolumn{2}{|c|}{ Wild $(N=82)$} & \multicolumn{2}{|c|}{ Synanthropic $(N=95)$} & \multirow[t]{2}{*}{ Overall } \\
\hline & Count & Frequency & Count & Frequency & \\
\hline L13-1 & 1 & 0.0061 & 0 & 0 & 0.0028 \\
\hline L13-2 & 2 & 0.0122 & 0 & 0 & 0.0056 \\
\hline L13-3 & 0 & 0 & 2 & 0.0105 & 0.0056 \\
\hline L13-4 & 0 & 0 & 1 & 0.0053 & 0.0028 \\
\hline L13-5 & 128 & 0.7805 & 154 & 0.8105 & 0.7966 \\
\hline L13-6 & 0 & 0 & 2 & 0.0105 & 0.0056 \\
\hline L13-7 & 15 & 0.0915 & 25 & 0.1316 & 0.1130 \\
\hline L13-8 & 5 & 0.0305 & 2 & 0.0105 & 0.0198 \\
\hline L13-9 & 0 & 0 & 1 & 0.0053 & 0.0028 \\
\hline L13-10 & 2 & 0.0122 & 0 & 0 & 0.0056 \\
\hline L13-11 & 4 & 0.0244 & 0 & 0 & 0.0113 \\
\hline L13-12 & 0 & 0 & 1 & 0.0053 & 0.0028 \\
\hline L13-13 & 3 & 0.0183 & 1 & 0.0053 & 0.0113 \\
\hline L13-14 & 1 & 0.0061 & 0 & 0 & 0.0028 \\
\hline L13-15 & 3 & 0.0183 & 0 & 0 & 0.0085 \\
\hline L13-16 & 0 & 0 & 1 & 0.0053 & 0.0028 \\
\hline L47-1 & 5 & 0.0305 & 10 & 0.0526 & 0.0424 \\
\hline L47-2 & 1 & 0.0061 & 1 & 0.0053 & 0.0056 \\
\hline L47-3 & 11 & 0.0671 & 24 & 0.1263 & 0.0989 \\
\hline L47-4 & 75 & 0.4573 & 60 & 0.3158 & 0.3814 \\
\hline L47-5 & 2 & 0.0122 & 0 & 0 & 0.0056 \\
\hline L47-6 & 7 & 0.0427 & 5 & 0.0263 & 0.0339 \\
\hline L47-7 & 1 & 0.0061 & 0 & 0 & 0.0028 \\
\hline L47-8 & 59 & 0.3598 & 86 & 0.4526 & 0.4096 \\
\hline L47-9 & 3 & 0.0183 & 4 & 0.0211 & 0.0198 \\
\hline
\end{tabular}


comparable $\left(\mathrm{F}_{\mathrm{ST}}=0,013\right.$, exact $\left.\mathrm{p}=0,09\right)$; an $\mathrm{F}_{\mathrm{ST}^{-}}$ based estimate of between-population migration suggests that about 20 reproductive individuals are exchanged per generation.

Taken together, these results all suggest that both wild and synanthropic populations belong to a single meta-population occurring across the study region. To further test this possibility, we conducted a Bayesian test of population subdivision using STRUCTURE 2.2. The analysis estimates and compares the likelihood of the data over a set of possible numbers of subdivisions $(\mathrm{K})$; we run 20 iterations for each $K$ value between 1 and 9, without a priori assignment of individuals to putative clusters. $\Delta \mathrm{K}$ was then calculated following Evanno et al. (2005): the most likely number of subdivisions corresponds to the $\mathrm{K}$ value that maximizes $\Delta \mathrm{K}$. In our case, as shown in Fig. 3, there was strong support for the existence of a single genetic cluster $(\mathrm{K}=1)$.

\section{DISCUSSION}

We have presented the first population-level analysis of microsatellite loci in R. ecuadoriensis, a locally important $C D$ vector that frequently reinvades and re-colonizes insecticide-treated households. The present study is a first step towards more detailed appraisals, which should include further polymorphic loci and the design of species-specific primer pairs (e.g., Fitzpatrick et al. 2008). The development of specific markers for R. ecuadoriensis is needed to improve our understanding of the vector's population dynamics, especially as wild populations seem to play a key role in CD transmission (Grijalva et al. 2014).

Even if still preliminary, the results of our analyses are suggestive of a single meta-population scenario in which $R$. ecuadoriensis migrants frequently move between sylvatic and artificial ecotopes - at a frequency high enough to homogenize both gene

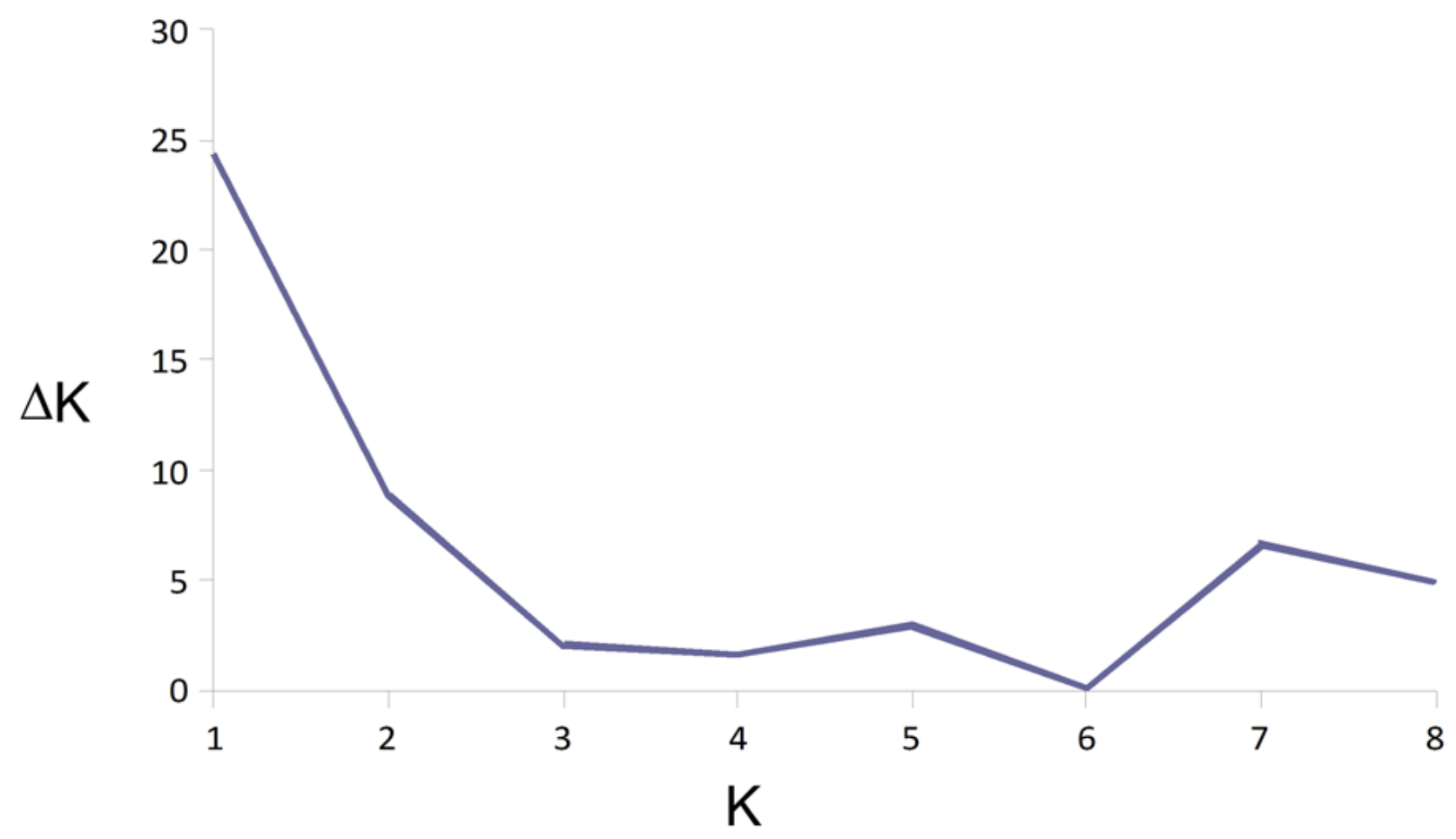

Figure 3. Estimation of the number of genetic subdivisions in Rhodnius ecuadoriensis populations from central western Ecuador. $K$, putative number of subdivisions; $\Delta K$, Bayesian statistic derived from the rate of change in the log-probability of the data, given each $K$ value. The peak value of $\Delta K$ at $K=1$ suggests that all specimens probably belong to a single meta-population. 
pools. This agrees with ecological and quantitative phenotypic assessments showing both frequent reinfestation of treated households (Grijalva et al., 2011, 2014) and a lack of morphological or morphometric differentiation of wild and synanthropic specimens (Villacís et al. 2010).

In line with previous findings (Grijalva et al. 2011), our data thus suggest that longitudinal surveillance will be a key requirement of long-term $\mathrm{CD}$ control in central coastal Ecuador. Entomological surveillance usually performs better when the community takes on an active role in reporting infestation (AbadFranch et al. 2011); however, a timely, professional response of vector control services is also needed, and this should include not only insecticide application but also environmental management of peridomestic ecotopes prone to harbor $\mathrm{R}$. ecuadoriensis breeding colonies - particularlypalm trees and chicken coops in our study setting (AbadFranch et al. 2005, Grijalva et al. 2011).

\section{CONCLUSIONS}

- Only two of six microsatellites developed for $R$. pallescens showed polymorphic loci in $R$. ecuadoriensis populations.

- $\quad$ Results of our analyses are suggesting only one genetic cluster is present in populations of $R$. ecuadoriensis in the province of Manabi, where migrants appear to move between sylvatic and artificial ecotopes.

\section{ACKNOWLEDGEMENTS}

Thisstudybenefitedfrominternationalcollaboration through the European Community-Latin American Network for Research on the Biology and Control of Triatominae (ECLAT) and the Trypanosoma cruzi Epidemiological Network (Chagas Epinet). Financial support was received from the European Union Seventh Framework Programme, contract number 223034 (ChagasEpiNet), Children's Heartlink Minneapolis (EEUU), Plan International Ecuador, Pontificia Universidad Católica del Ecuador (Grant \# E13027, G13026, H13174) and the Ecuadorian Ministry of Public Health. We thank the HSC core research facility, University of Utah and the field entomologists from the National Chagas Control Program, Ministry of Public Health, Ecuador. Technical assistance was provided by Anita G. Villacis, César Yumiseva, Jaime A. Costales, Sofía Ocaña-Mayorga, and David Terán, Center for Infectious Disease Research, Pontifical
Catholic University of Ecuador (PUCE). We also thank MS Llewellyn for his comments on a draft version of the manuscript. FA-F acknowledges support from the Centro de Pesquisa René Rachou - Fiocruz.

\section{REFERENCIAS BIBLIOGRAFICAS}

Abad-Franch, F., Monteiro, F.A., Jaramillo, N., Gurgel-Gonçalves, R., Dias, F.B.S., Diotauiti,

L. 2009. Ecology, evolution, and the long-term surveillance of vector-borne Chagas disease: a multi-scale appraisal of the tribe Rhodniini (Triatominae). Acta Tropica 110: 159-177.

Abad-Franch, F., Palomeque, F.S., Aguilar, H.M., Miles, M.A. 2005. Field ecology of sylvatic Rhodnius populations (Heteroptera, Triatominae): Risk factors for palm tree infestation in western Ecuador. Tropical Medicine \& International Health10: 1258-1266.

Abad-Franch, F., Paucar, C. A., Carpio, C.C., Cuba Cuba, C.A., Aguilar, H.M., Miles, M.A. 2001. Biogeography of Triatominae (Hemiptera: Reduviidae) in Ecuador: implications for the design of control strategies. Memórias do Instituto Oswaldo Cruz 96: 611-620.

Abad-Franch, F., Vega, M.C., Rolón, M.S., Santos, W.S., Rojas de Arias, A. 2011. Community participation in Chagas disease vector surveillance: systematic review. PLoS Neglected Tropical Diseases 5: e1207.

Evanno, G., Regnaut, S., Goudet, J. 2005. Detecting the number of clusters of individuals using the software STRUCTURE: a simulation study. Molecular Ecology 14: 2611-2620.

Excoffier, L. Laval, G., Schneider, S. 2005:. Arlequin (version 3.0): An integrated software package for population genetics data analysis. Evolutionary Bioinformatics Online 1: 47-50.

Fitzpatrick, S., Feliciangeli, M.D., Sanchez-Martin M.J., Monteiro, F.A., Miles M.A. 2008. Molecular genetics reveal that silvatic Rhodnius prolixus do colonise rural houses. . PLoS Neglected Tropical Diseases 2: e210.

Grijalva, M.J., Palomeque-Rodríguez, F.S., Costales, J.A., Dávila, S., Arcos-Terán L. 2005. High household infestation rates by synanthropic vectors of Chagas disease in southern Ecuador. 
Journal of Medical Entomology 42, 68-74.

Grijalva, M.J., Villacís, A.G., Ocaña-Mayorga, S., Yumiseva, C.A., Baus, E.G. 2011. Limitations of selective deltamethrin application for triatomine control in central coastal Ecuador. Parasites \&Vectors, 4: 20.

Grijalva, M.J., Suarez-Davalos, V., Villacis, A.G., Ocana-Mayorga, S., Dangles, O. 2012. Ecological factors related to the widespread distribution of sylvatic Rhodnius ecuadoriensis populations in southern Ecuador. Parasites \& Vectors 5: 17.

Grijalva, M. J., Terán, D., \& Dangles, O. 2014. Dynamics of Sylvatic Chagas Disease Vectors in Coastal Ecuador Is Driven by Changes in Land Cover. PLoS Neglected Tropical Diseases 8(6):e2960.

Harry, M., Poyet, G., Romaña, C.A., Solignac, M. 1998. Isolation and characterization of microsatellite markers in the blood sucking bug Rhodnius pallescens (Heteroptera, Reduviidae). Molecular Ecology 7: 1771-1788.

Pritchard, J.K., Stephens, P., Donnelly, P. 2000. Inference of population structure using multilocus genotype data. Genetics 155: 945-959.

Suárez-Dávalos, M.V., Dangles, O., Villacís, A.G., Grijalva, M.J. 2010. Microdistribution of sylvatic triatomine populations in central-coastal Ecuador. Journal of Medical Entomology 47: 80-88.

Villacís, A.G., Grijalva, M.J., Catalá, S.S. 2010. Phenotypic variability of Rhodnius ecuadoriensis populations at the Ecuadorian central and southern Andean region. Journal of Medical Entomology 47: 1034-1043. 
